\title{
Motivação e Evasão na Carreira Militar: um estudo de caso no Exército Brasileiro
}

\author{
João Nelson Raimundo ${ }^{1}$; Jorge da Silva Correia Neto ${ }^{2}$
}

\begin{abstract}
Resumo: Os estudos sobre a motivação humana no ambiente de trabalho remontam ao início dos estudos organizacionais, sejam eles em organizações públicas ou privadas. Neste sentido o presente estudo versa sobre motivação em um tipo de instituição pública, o Exército Brasileiro, tendo em vista que a desmotivação de profissionais desse tipo de instituição pode ensejar na perda de investimentos feitos ao longo de anos. Num estudo de caso no $9^{\circ}$ Grupo de Artilharia de Campanha - MS estudamos a categoria de sargentos, numa pesquisa qualitativa onde via grupo focal buscamos identificar o que motiva essa categoria e ainda sugerir ações para diminuir a evasão. Os resultados apontaram que estabilidade, transferências, valorização do militar perante a sociedade civil, missões no exterior, por exemplo, são grandes motivadores, mas a questões salariais e do plano de carreira desmotivam. Também foram apontadas sugestões de melhoria.
\end{abstract}

Palavras chave: Motivação, Evasão, Exército, Administração Pública.

\section{Motivation and Military Career Evasion: A case study in the Brazilian Army}

\begin{abstract}
Studies on human motivation in the workplace back to the early organizational studies, whether in public or private organizations. In this sense, the present study is about motivation in a type of public institution, the Brazilian Army, considering that the demotivation of professionals of this type of institution can lead to the loss of investments made over the years. In a case study in the 9th Campaign Artillery Group - MS, we studied the category of sergeants, in a qualitative research where the focus group sought to identify what motivates this category and also suggest actions to reduce evasion. The results pointed out that stability, transfers, valorization of the military before civil society, missions abroad, for example, are great motivators, but salary issues and the career plan discourage. Suggestions for improvement were also mentioned.
\end{abstract}

Keywords: Motivation, Evasion, Army, Public Administration.

\section{Introdução}

Seja no contexto público ou privado, o fenômeno da motivação para o trabalho tem tido grande relevância nos estudos organizacionais. Dentre os estudiosos da motivação destacam-se Maslow, Herzberg e McGregor, que muito influenciaram na construção das bases do Comportamento Organizacional. Como ponto inicial de discussão, podemos afirmar que motivação é uma força interior, impulso ou intenção que leva uma pessoa a fazer algo ou agir de certa forma (MAGILL, 1984).

\footnotetext{
${ }^{1}$ Acadêmico de Administração Pública da Universidade Federal Rural de Pernambuco. Contato: joaopgmca@hotmail.com;

${ }^{2}$ Professor adjunto da Universidade Federal Rural de Pernambuco, curso de bacharelado em Administração Pública a distância pela UABUFRPE. Graduado em Administração pela UFPE, especialista em Docência do Ensino Superior pela FADEPE, mestre em Administração pela UFPE e doutor em Administração pela UFPE. Contato: jorgecorreianeto@ gmail.com.
} 
Seguindo a linha cognitivista de Lewin (1936), que considera que as influências do meio onde o indivíduo está localizado determinam o grau de sua motivação, Robbins (2004) afirma que a motivação também resulta da interação entre o indivíduo e a situação. Considerando a situação, o indivíduo é influenciado por este fator, no ambiente organizacional e fora dele. Sendo assim, pode-se afirmar que a situação dentro de uma organização pode influenciar na vida profissional do trabalhador, positivamente ou negativamente, afetando seu nível de motivação e satisfação ao trabalho.

Como ações de valorização profissional do servidor, principalmente aquelas voltadas para suas atividades no cargo, tendem a diminuir a rotatividade, não só pela estabilidade garantida legalmente (CAFFÉ FILHO; GONÇALVES; SANTOS, 2017), decidimos tomar como campo de pesquisa uma instituição pública específica, no caso o Exército Brasileiro, para avaliar como o fenômeno da motivação reflete no dia a dia da corporação e como a falta dessa motivação pode levar à evasão. Tomamos por base o $9^{\circ}$ Grupo de Artilharia de Campanha, organização militar do Exército Brasileiro, representada pelo Ministério da Defesa e pertencente à administração pública federal direta.

Não apenas no Exército, mas em todas as Forças Armadas, é percebido que, muitas vezes, o clima de insatisfação nas tropas militares pode influenciar o desempenho profissional de cada um dos componentes (RESERVAER, 2017). Problemas como salários defasados, transferências indesejadas, escala de serviço, demora nas promoções, o interesse de outras empresas no potencial do militar, dentre outros, são fatores que vem levando os sargentos, por exemplo, a buscar outras profissões.

Segundo publicação da Revista Sociedade Militar (SM, 2016), a falta de representação política é o principal motivo de descontentamento, tanto na categoria dos Oficiais quanto dos Sargentos. Esta situação gera, por sua vez, os questionamentos citados anteriormente, que levam os militares à insatisfação e, muitas vezes, à evasão.

Levando em consideração este risco de evasão de Sargentos do Exército brasileiro, a busca da compreensão dos fatores motivacionais que levam a esse problema existente no meio militar pode ser uma excelente premissa para que o Comando da instituição, juntamente com sua Gestão Estratégica e de Recursos Humanos, desenvolva um trabalho de planejamento motivacional para suas tropas, no que diz respeito ao sargento. Vale frisar que a elevação do 
grau de satisfação dos integrantes de qualquer exército é de suma relevância para o comando, para o subordinado, qualquer seja sua esfera hierárquica, e também para a organização em si.

Nesse contexto, o $9^{\circ}$ Grupo de Artilharia de Campanha, a única organização militar especializada em Artilharia de Campanha no Estado do Mato Grosso do Sul, com sede na cidade de Nioaque, está dotado de recursos humanos e operacionais e enquadra-se num adequado campo de pesquisa referente à motivação dos militares. A partir disso, esse estudo sobre motivação está voltado para os sargentos que atuam na área da administração pública dessa organização militar, buscando responder a seguinte questão de pesquisa: como está a satisfação desses militares e quais são os fatores que tem levado muitos deles a procurar outras profissões, de cunho público ou privado?

Assim, esse estudo tem como objetivo geral apontar os fatores motivacionais que interferem no desempenho das funções dos sargentos. Para tanto, foram traçados os seguintes objetivos específicos:

1. Descrever as características funcionais dos sargentos de carreira que atuam no âmbito administrativo;

2. Identificar os fatores que interferem na motivação dos sargentos de carreira para o trabalho;

3. Avaliar o grau de satisfação e os pontos positivos e negativos dos sargentos quanto à profissão militar.

A partir desta Introdução, o presente estudo está estruturado em cinco seções. A seção 2 apresenta o Referencial Teórico trazido para o estudo e a seção 3 apresenta o Percurso Metodológico utilizado para realizar a pesquisa. A seção 4 apresenta dos Resultados obtidos e a seção 5 apresenta as principais Conclusões a que se pode chegar nesse momento.

\section{Motivação}

Para Magill (1984), a motivação está ligada ao comportamento humano, dando-lhe sentido e direção, sendo uma força interior, impulso ou intenção que leva uma pessoa a fazer algo ou agir de certa forma. Assim, são definidos o direcionamento das ações e a intensidade dos esforços individuais para atingir uma determinada meta e, neste sentido, cabe ao gestor 
pode designar as atribuições e recompensas mais eficazes para seus liderados (ALVES; SILVA; OLIVEIRA, 2017).

Segundo o manual militar "Instruções Provisórias IP 20-10" (1991), motivação é a força interna que emerge, regula e sustenta todas as ações humanas. É um impulso interior que leva as pessoas a realizarem coisas. $\mathrm{O}$ alto grau de motivação num indivíduo faz com que ele utilize ao máximo seus conhecimentos, habilidades e aptidões para alcançar os objetivos previstos. Mesmo que ele seja menos dotado, com menos potencial para executar algo, conseguirá produzir melhor e com maior intensidade do que alguém com menos interesse em executar uma tarefa, mesmo que este último seja mais capacitado.

No âmbito organizacional, a motivação traz grande influência sobre a produtividade e deve ser considerada quando a finalidade é alcançar objetivos organizacionais (ROBBINS, 2004). O autor ainda enfatiza que a motivação é a vontade de exercer altos níveis de esforços para a obtenção desses objetivos.

Além disso, nas organizações existe uma interação entre as forças do meio ambiente que incidem sobre o ego das pessoas inseridas e as forças internas desses indivíduos. Tomando como exemplo, uma organização militar, o IP 20-10 (1991, p. 21) ressalta que

fatores individuais afetam o nível de motivação que Unidades e soldados apresentam, o qual depende também do envolvimento com os propósitos e metas da organização. Estes propósitos e metas, por sua vez, influenciam a intensidade dos esforços de cada um.

O líder, em geral, deve estar sempre motivado para que possa motivar seus subordinados, pois como aponta o IP 20-10 (1991, p. 21),

Para motivar os subordinados, o líder utiliza seus conhecimentos sobre a natureza humana, orientado e motivado por suas crenças, valores profissionais e suas próprias características pessoais, aplicando os princípios da liderança. Deste modo, o chefe e cria uma atmosfera ética e de liderança que dinamiza e motiva os subordinados a alcançarem as metas estabelecidas.

Bergamini (1997) diz que é possível motivar as pessoas através do conhecimento das suas necessidades individuais, para assim oferecer subsídios que satisfaçam suas necessidades. Com isso, os gestores não devem somente preocupar-se em elaborar estratégias 
que motivem seus subordinados; é fundamental que exista um ambiente de trabalho favorável, trazendo aos liderados um bom nível de motivação e, por fim, de satisfação.

Considerando essas premissas, o estudo da motivação nas organizações é de grande relevância, por isso a seguir apresentamos as principais linhas de estudo sobre o tema.

\section{Teoria Motivacional de Maslow}

Maslow (1943) explicou que, na base da pirâmide, estão as necessidades de nível mais elementar, enquanto no topo encontram-se as necessidades que representam o ápice de todas elas; o homem é motivado no sentido de satisfazer um conjunto de necessidades, conforme esta hierarquia de importância entre elas.

Assim, a motivação humana é explicada através de cinco tipos de necessidades, que compõem esta pirâmide hierárquica (GIL, 2001):

- Necessidades fisiológicas - referem-se à alimentação, abrigo e vestuário, sendo básicas à vida do ser humano. Se não forem satisfeitas, as outras necessidades estarão comprometidas, pois as pessoas darão pouca atenção às necessidades posteriores;

- Necessidades de segurança - correspondem à necessidade de sentir-se seguro, livre dos perigos e ainda seguro com relação à manutenção do emprego e da propriedade;

- Necessidades sociais - diz respeito à necessidade de interação entre as pessoas, da participação social e delas serem aceitas num grupo;

- Necessidades de estima - referem-se à estima, envolvendo o amor próprio e o reconhecimento pelas outras pessoas. É o desejo maior, mais do que participar de um grupo; e

- Necessidades de autorrealização - correspondem ao potencial e ao desejo que o indivíduo tem de se tornar algo. Por exemplo, um dia se tornarem chefes.

A Figura 1 ilustra a Teoria das Necessidades Humanas proposta por Maslow (1943). 


\section{Pirâmide das Necessidades Humanas de Maslow}

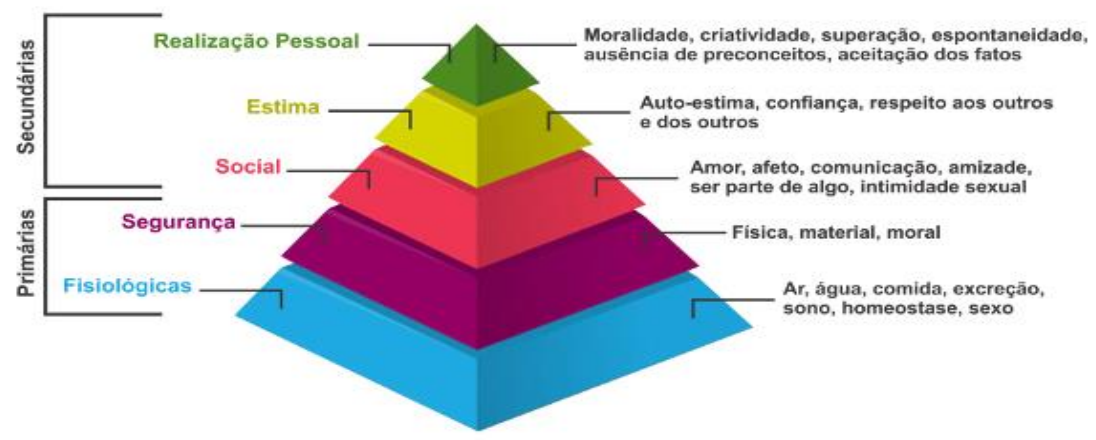

Figura 1:Pirâmide das Necessidades Humanas de Maslow Fonte: Eugênio (2016).

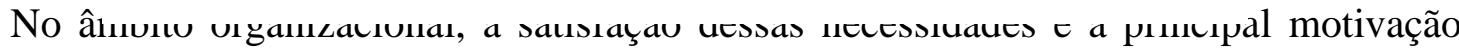
para o comportamento das pessoas dentro das organizações. Percebe-se, segundo a Teoria de Maslow, que as pessoas não necessitam apenas de satisfações financeiras, mas também de respeito e de atenção dos que convivem ao seu redor. Enfim, os gestores precisam considerar que as pessoas inseridas numa organização tendem a progredir de acordo com suas necessidades, procurando satisfazer todas elas, até conseguirem o alto nível das necessidades, que é a autorrealização (MAXIMIANO, 2007).

\section{Teoria dos Fatores Higiênicos e Motivadores de Herzberg}

Herzberg (1975) procurou aliar motivação ao comportamento humano em situações de trabalho, apontando fatores higiênicos (extrínsecos) e os motivadores (intrínsecos). Os fatores higiênicos satisfazem as necessidades fisiológicas, de segurança e sociais. Enquadram-se nessa categoria o salário, os modelos de gestão, os benefícios sociais, as condições de trabalho e o relacionamento com os companheiros de trabalho. 
Vergara (2003) afirma que, quando estes fatores estão ausentes, deixam de causar insatisfação nas pessoas, sem causar satisfação. Já Bergamini (1982) salienta que os fatores higiênicos não fazem as pessoas produzirem mais, mas evitam a insatisfação no ambiente de trabalho.

Já os fatores motivacionais (intrínsecos) envolvem reconhecimento e autorrealização. Para fins de exemplificação, podemos citar a realização profissional, a possibilidade de ascensão a um cargo, o crescimento profissional, o desafio do trabalho em si e o reconhecimento por uma tarefa bem sucedida (HERZBERG, 1975). O enriquecimento do trabalho resulta em crescimento individual, trazendo desafios e maior satisfação profissional ao trabalhador (HERZBERG, 1968).

Vergara (2003) ainda afirma que estes fatores, quando presentes, ocasionam satisfação, porém, quando ausentes, não causam satisfação, mas também não causam insatisfação. Bergamini (1982) acrescenta que os fatores motivacionais aumentam o nível de satisfação no trabalho, quando proporcionados de forma condizente.

\section{Teoria X e Teoria Y de Mcgregor}

A teoria comportamental focaliza, principalmente, a percepção e a visão dos gestores em relação ao comportamento humano no ambiente de trabalho. Para McGregor (1992), a Teoria X corresponde às ideias tradicionais e conservadoras sobre o comportamento dos indivíduos no trabalho, de que as pessoas não gostam de trabalhar e desenvolvem suas atividades perante coação, ameaça de castigos ou punições, e que têm pouca ambição e procuram segurança acima de tudo.

Por sua vez, a Teoria Y, segundo, tem em sua base a integração entre os objetivos individuais os organizacionais, permitindo um maior autocontrole quando essa integração ocorre (FERREIRA; PEREIRA; REIS, 2002; McGREGOR, 1992). Com a Teoria Y os gestores podem desenvolver um modelo voltado para a flexibilidade e para o dinamismo, com mais oportunidades, removendo obstáculos e preconizando a iniciativa pessoal. 


\section{Uma Visão Geral sobre o Campo de Estudo}

Em qualquer organização pública ou privada, a preocupação com a motivação no trabalho é de fundamental importância em diversos campos de estudo, sobretudo no ramo da Administração Pública. No contexto deste estudo as Forças Armadas estão conceituadas no art. $1^{\text {o }}$ da Lei Complementar nº 97/1999 (BRASIL. 1999, online):

\footnotetext{
As Forças Armadas, constituídas pela Marinha, pelo Exército e pela Aeronáutica, são instituições nacionais permanentes e regulares, organizadas com base na hierarquia e na disciplina, sob a autoridade suprema do Presidente da República e destinam-se à defesa da Pátria, à garantia dos poderes constitucionais e, por iniciativa de qualquer destes, da lei e da ordem.
}

A instituição é considerada fechada, de estrutura linear e é baseada em dois princípios - a hierarquia e a disciplina. Para cumprir sua missão, a motivação é algo bem característico na vida do militar em si. O sargento de carreira deve acima de tudo estar motivado a cumprir uma missão delegada pelo seu comandante (Oficiais), além de procurar motivar os seus subordinados (cabos e soldados) a cumpri-la com eficiência.

A instituição oferece diversos benefícios, como a estabilidade, salário pontual, assistência médica e odontológica extensiva aos familiares, etc., o que muitos jovens para a carreira militar. Porém, muitos recém-ingressados terminam optando por outras profissões públicas ou privadas, o que justifica a necessidade deste estudo a fim de levantar os fatores que elevam a motivação dos sargentos e os que os levam à evasão para outras profissões. Acredita-se que o estudo contribuirá para a elaboração de programas do Departamento Geral de Pessoal, órgão que constitui os Recursos Humanos da instituição, e ainda poderá gerar alternativas para se minimizar as perdas de efetivo de sargentos para outras carreiras.

O $9^{\circ}$ Grupo de Artilharia de Campanha - Grupo Major Cantuária é única unidade especializada em Artilharia de Campanha do Exército Brasileiro, situada no Estado do Mato Grosso do Sul, estando sediado na cidade de Nioaque. Este aquartelamento está situado na divisão territorial da $9^{\text {a }}$ Região Militar, sendo subordinada à $4^{\text {a }}$ Brigada de Cavalaria Mecanizada, com sede em Dourados - MS. Essa Brigada, por sua vez, está subordinada ao Comando Militar do Oeste.

Como missão, o $9^{\circ}$ Grupo de Artilharia de Campanha apoia pelo fogo a $4^{\text {a }}$ Brigada de Cavalaria Mecanizada, em operações de defesa externa, atua em ações de prevenção e 
repreensão a delitos transfronteiriços, e forma um contingente mobilizável, em condições de ser empregado em ações de defesa externa e combate aos crimes transfronteiriços.

Segundo o Chefe da $1^{\text {a }}$ Seção do $9^{\circ}$ GAC, encarregado pelo setor de pessoal, a organização conta com 400 militares, sendo 20 Oficiais de carreira, 100 praças de carreira (Subtenentes e Sargentos) e 280 Cabos e Soldados, ao todo. Anualmente, 70 recrutas, que compõem o chamado "efetivo variável”, em média, cumprem o Serviço Militar Obrigatório, passam a receber instruções de cunho militar, alojamento, fardamento e assistência médica e religiosa, durante o período previsto de um ano. Dentre esses militares, os que alcançam maior destaque e são voluntários, podem receber, diante a necessidade de vagas, a prorrogação de tempo de serviço por um ano, podendo chegar até sete.

Como aponta o Estatuto dos Militares, Lei No 6800/2002, em seu Art. 14, "A hierarquia e a disciplina são a base institucional das Forças Armadas. A autoridade e a responsabilidade crescem com o grau hierárquico”. Além disso, o Regulamento Disciplinar do Exército (RDE) - R4 (2002), em seu artigo $7^{\circ}$ diz que "A hierarquia militar é a ordenação da autoridade, em níveis diferentes, por postos e graduações" e no artigo $8^{\circ}$ aponta que "A disciplina militar é a rigorosa observância e o acatamento integral das leis, regulamentos, normas e disposições, traduzindo-se pelo perfeito cumprimento do dever por parte de todos e cada um dos componentes do organismo militar.”.

Rêgo (2012, online) ainda afirma que "a disciplina é o regime que torna possível o funcionamento da organização, facilita as relações de subordinação entre os militares e permite a observância das leis, regulamentos, diretrizes, preceitos, normas, ordens etc." Assim, a "Hierarquia e a Disciplina são preservadas em todas as situações, dentro ou fora do quartel por militares da ativa, da reserva ou reformados.”. Além disso, são consideradas organizações totais, pois envolvem todas as dimensões da vida de seus membros e constroem identidades mais fortes que, quando plenamente desenvolvidas, requerem de seus membros uma radical transformação de personalidade (CARVALHO, 2005). 


\section{Metodologia}

Baseado em Prodanov e Freitas (2013), quanto à natureza a presente pesquisa caracteriza-se como aplicada, pois objetiva gerar conhecimentos para aplicação prática, dirigidos à solução de problemas específicos, e quanto aos objetivos é descritiva, pois visa registrar e descrever os fatos observados sem interferir neles. Segundo Minayo e Sanches (1993), quanto à abordagem esta pesquisa tem caráter qualitativo, pois tem o ambiente como fonte direta dos dados.

O instrumento de coleta de dados utilizado na pesquisa foi o grupo focal. Segundo Morgan (1997), grupos focais são utilizados em pesquisas qualitativas, derivada das entrevistas grupais, coletando informações por meio das interações grupais visando reunir informações sobre um tópico específico a partir de um grupo específico selecionado.

O grupo focal entrevistou 15 Sargentos de Carreira do Grupo Major Cantuária na discussão do tema da pesquisa. Primeiramente foi apresentada pelo pesquisador, que atuou como facilitador, a visão geral e os objetivos do assunto. Na sequência foram feitas algumas perguntas iniciais aos participantes e, em seguida, foram realizadas perguntas com os objetivos específicos da pesquisa, de modo que os participantes discutissem, revelando seus pensamentos e opiniões, com duração de um encontro de uma hora a cada três dias. Por fim o pesquisador resumiu as informações discutidas e tirou dúvidas.

Para fins de interpretação desses dados foi realizada a análise de conteúdo. Para Bardin (1979), a análise de conteúdo possibilita uma análise objetiva e sistemática dos discursos ocorridos, sendo para tanto preciso realizar um processo de quatro etapas: i) préanálise, que envolve a organização dos textos gerados a partir das transcrições das entrevistas e dos documentos coletados; codificação, que implementa a transformação sistemática dos dados brutos coletados em unidades agregadas que devem traduzir com exatidão as características do conteúdo; categorização, que envolve uma operação de classificação a fim de criar as categorias de análise, fundamentada em teorias ou eventos anteriores ou ainda idealizada pelo pesquisador, seguindo critérios semânticos, sintáticos, léxicos ou expressivos; e por fim a análise, onde os resultados obtidos são interpretados. 


\section{Resultados}

Foi realizada uma palestra sobre os assuntos que seriam tratados e posteriormente três encontros de grupo focal, onde foi possível coletar os dados. Em cada encontro foi trabalhada uma temática específica: quais são fatores motivacionais intrínsecos e extrínsecos (profissionais e não profissionais) que influenciam a carreira do sargento? Quais os motivos que tem levado os militares a desistirem da carreira militar e buscar outras profissões? Quais são as ações que os sargentos têm realizado para buscar motivação na carreira militar?

Sobre os dois primeiros questionamentos, antes de apresentar a pergunta foram exemplificados fatores intrínsecos, extrínsecos e os que levariam à evasão dos militares, para que os sargentos então expusessem suas opiniões e trouxessem novas contribuições. Quanto à terceira pergunta, eles discutiram diretamente. Os participantes puderam elencar quais eram os fatores de cada categoria que mais influenciavam em suas motivações, permitindo que o pesquisador pudesse fazer depois a análise dos dados citados. O Quadro 1 sintetiza essas discussões a partir da análise de conteúdo realizada.

Quadro 1: Respostas dos participantes sobre aos fatores motivacionais intrínsecos, extrínsecos e de evasão.

\begin{tabular}{|c|c|c|c|}
\hline \multirow[b]{2}{*}{ Fatores intrínsecos } & \multicolumn{2}{|c|}{ Fatores extrínsecos } & \multirow[b]{2}{*}{ Fatores de evasão } \\
\hline & Profissionais & Não-profissionais & \\
\hline Missões no exterior & $\begin{array}{l}\text { Reconhecimento dos } \\
\text { superiores e da própria } \\
\text { instituição }\end{array}$ & $\begin{array}{l}\text { Disponibilidade de } \\
\text { moradia na guarnição } \\
\text { (Próprio Nacional } \\
\text { Residencial) }\end{array}$ & Escala de serviço \\
\hline $\begin{array}{l}\text { Possibilidade de } \\
\text { realização de cursos e } \\
\text { especializações }\end{array}$ & Ambiente de trabalho & $\begin{array}{l}\text { Assistência médica e } \\
\text { odontológica }\end{array}$ & $\begin{array}{l}\text { Salário em relação à } \\
\text { outras carreiras públicas }\end{array}$ \\
\hline $\begin{array}{l}\text { Promoções } \\
\text { merecimento }\end{array}$ & Status & $\begin{array}{l}\text { Satisfação pessoal e } \\
\text { familiar }\end{array}$ & $\begin{array}{l}\text { Incompetência de alguns } \\
\text { comandantes }\end{array}$ \\
\hline $\begin{array}{l}\text { Valores militares } \\
\text { (patriotismo, amor à } \\
\text { profissão, espírito de } \\
\text { corpo, camaradagem, } \\
\text { civismo) }\end{array}$ & Transferências & $\begin{array}{l}\text { Infraestrutura da cidade } \\
\text { onde serve }\end{array}$ & $\begin{array}{l}\text { Obsolência do material de } \\
\text { emprego militar }\end{array}$ \\
\hline Progresso profissional & Estabilidade & $\begin{array}{l}\text { Valorização do militar } \\
\text { pela sociedade civil }\end{array}$ & $\begin{array}{l}\text { Transferências para } \\
\text { guarnições indesejadas }\end{array}$ \\
\hline Missões no exterior & Diárias e representações & $\begin{array}{l}\text { Atividades sociais com a } \\
\text { família }\end{array}$ & $\begin{array}{l}\text { Plano de carreira das } \\
\text { praças }\end{array}$ \\
\hline $\begin{array}{l}\text { Possibilidade de } \\
\text { conhecer cidades }\end{array}$ & Liderança do chefe & $\begin{array}{l}\text { Programas sociais } \\
\text { oferecidos pela } \\
\text { instituição }\end{array}$ & $\begin{array}{l}\text { Frustração com a carreira } \\
\text { após a formação na escola }\end{array}$ \\
\hline
\end{tabular}


Sobre os fatores motivacionais intrínsecos, explicitados na tabela, pode-se observar o seguinte de cada resposta:

- Missão no exterior - um dos requisitos para concorrer a este tipo de missão é a especialização em idiomas cuja exigência é abordada pela Portaria No 577/2003, que aprova as Instruções Gerais para as Missões no Exterior - IG 10-5. Dos entrevistados, 4 sargentos estavam em busca dessa especialização e 3 já estiveram em Missões de Paz no Haiti. A maioria alegou que esse desejo envolve questões de realizações financeiras;

- Possibilidade de realização de cursos e especializações - dentre os cursos mais almejados estão o Curso Básico Paraquedista e de Artilharia Antiaérea para Sargentos. O primeiro é bastante desejado pela 'mística' paraquedista, famosa no Exército, o que eleva a moral e o reconhecimento por muitos, devido às dificuldades do curso; o outro, pelo fato da possibilidade de conhecer outro tipo de Artilharia, já que a formação do sargento artilheiro na escola de formação é baseada em Artilharia de Campanha. Dos entrevistados, 2 tinham o curso de paraquedismo militar e 3 eram antiaéreos. Os demais ainda iriam solicitar os cursos;

- Promoções por merecimento - todos os militares entrevistados têm preocupação com a avaliação de seu desempenho, procurando ser um dos melhores profissionais, a fim da elevação de seus conceitos perante seus superiores. Na época da promoção, eles sabem que isso irá influenciar na pontuação para promoção a $2^{\circ}$ Sargento por merecimento;

- Valores militares - durante a discussão, esta questão foi bastante relevante, pois os sargentos alegaram que, na sociedade atual, onde existe a evidência de problemas sociais e de inversões de valores, a instituição consegue preservar valores essenciais na vida do ser humano e até em relação a outros tipos de organizações;

- Progresso profissional - para os militares entrevistados, o progresso profissional os motiva, devido às oportunidades oferecidas pela instituição: cursos, missões no exterior, possibilidade de conhecer novas cidades, etc.; 
- Possibilidades de conhecer novas cidades - o fato de conhecer várias cidades de diversas regiões do Brasil, ou até no exterior, aumenta o ego do sargento, tanto que muitos alegaram que a escolha pelo militarismo foi relevante devido a esse fator.

$\mathrm{Na}$ análise dos fatores motivacionais extrínsecos, os sargentos alegaram, no âmbito profissional, que sentem motivados por esses fatores, devido aos seguintes motivos:

I- Reconhecimento dos superiores e da própria instituição - no sentido de elevar a autoestima do militar;

II- Transferências - além da possibilidade de conhecer novas cidades, o militar recebe um adicional extra no salário para fins de movimentação;

III- Estabilidade - a concessão vem após 10 anos de serviço ativo para o sargento adquirir a estabilidade na carreira, mas mesmo assim este fator é relevante, pois alegaram que não gostariam de estar numa carreira privada, onde é possível ser demitido a qualquer momento;

IV- Diárias e representações - sentem-se motivados a cumprir missões fora da guarnição onde servem, pois sabem que esses dois fatores envolvem questões salariais; V- Liderança do chefe - sentem-se motivados quando têm um chefe que entende o lado psicológico da tropa e demonstra carisma no convívio militar.

Os fatores motivacionais extrínsecos não ligados à profissão estão voltados para o bem estar do círculo de militares e seus dependentes:

- Disponibilidade de moradia - os Próprio Nacional Residencial (PNR) são as moradias disponíveis para os militares que servem numa guarnição. Os sargentos do $9^{\circ}$ GAC optaram por escolher a guarnição de Nioaque, devido ao alto índice de disponibilidade de PNR;

- Satisfação pessoal e familiar - esse fator advém do fato da conquista da autorrealização própria e da família estar bem;

- Assistência médica e odontológica - é um fator de grande relevância entre os militares entrevistados, pois consideraram que essa assistência é bastante acessível por questões de custos em comparação aos planos de saúde privados ou de outras instituições públicas; 
- Infraestrutura da cidade onde servem - há preocupação com os dependentes: escola de qualidade para os filhos, existência de universidades, emprego para as esposas, etc.;

- Valorização do militar pela sociedade civil -afirmaram que a Nação os elogia pelos feitos na História, na defesa territorial e nas intervenções em garantia da lei e da ordem;

- Atividades sociais com a família - passeios, eventos militares e reuniões foram alguns exemplos citados, trazendo um nível de satisfação maior para os militares e suas famílias;

- Programas sociais oferecidos pela instituição - o apoio em situações de calamidade pública, em setores da educação e da saúde em lugares inóspitos do Brasil, a distribuição de água no Nordeste, as obras de engenharia em algumas regiões do país foram citados.

Quanto aos fatores que os tem desmotivado surgiram as seguintes respostas:

- Escala de serviço - muitos não se adaptam a esse fator, pois não obtém recompensas pelo "serviço tirado", com relação ao Comando (as próprias leis que regulamentam o serviço são ultrapassadas), e ainda tem que cumprir o expediente do dia seguinte.

- Salário em relação a outras carreiras públicas - o salário das Forças Armadas está em defasagem, e muitos sargentos estudam para outros concursos;

- Incompetência de alguns comandantes - falta de liderança perante os subordinados;

- Obsolescência do material de emprego militar - muito armamento ainda é o mesmo usado na $2^{\mathrm{a}}$ Guerra Mundial, mas reconheceram que há investimento em novos equipamentos;

- Transferência para guarnições indesejadas - este representa um dos maiores problemas na carreira do militar, pois na escolha do plano de transferência todos desejam ser transferidos em pelo menos na quinta opção de escolha de cidade para servir, num plano de dez opções, por exemplo. Quando isso não ocorre, processos administrativos para reverter este tipo de situação começam a vigorar.

- Plano de carreiras das praças - constitui-se em mais um item de desmotivação, devido ao longo tempo para promoção de sargentos, à desvalorização daqueles que possuem curso superior, e ao tempo de estabilidade; 
- Frustração com a carreira após a formação na escola - muitos ainda alunos da escola de formação desistem da carreira, por não se adaptarem ao regime militar.

Dentre os fatores desmotivadores que podem levar à evasão dos sargentos de carreira, foram levantados, como demonstra o quadro abaixo, algumas oportunidades de melhorias, visando motivar o trabalho desses militares dentro da organização:

Quadro 2: Oportunidades de melhorias sobre os fatores desmotivadores

\begin{tabular}{|c|c|}
\hline Escala de serviço & $\begin{array}{l}\text { Propor ao Comando um dia de folga para o sargento, após um serviço de } 24 \\
\text { oras, proporcionando ao militar um descanso maior. }\end{array}$ \\
\hline $\begin{array}{l}\text { Salário em relação a } \\
\text { outras carreiras }\end{array}$ & $\begin{array}{l}\text { - Realização de reuniões entre o Comandante da unidade com o escalão superior } \\
\text { do Exército, a fim de rever a política salarial da categoria; } \\
\text { - Contribuição da organização na educação financeira dos sargentos, ensinando a } \\
\text { trabalhar com o dinheiro que recebem. }\end{array}$ \\
\hline Incomp & - Ministrar instruções sobre liderança militar para os comandantes. \\
\hline $\begin{array}{l}\text { Obsolescência do } \\
\text { material de emprego } \\
\text { militar }\end{array}$ & $\begin{array}{l}\text { - Demonstrar para a categoria dos sargentos, por meio de palestras, as aquisições } \\
\text { de novos materiais de emprego militar feitas pelo Exército; } \\
\text { - Incentivar o aperfeiçoamento no uso de novos materiais, via cursos e estágios. }\end{array}$ \\
\hline $\begin{array}{r}\text { Tran } \\
\text { guarniç }\end{array}$ & $\begin{array}{l}\text { - Proporcionar ao sargento, dentro das possibilidades da Força, a revogação da } \\
\text { transferência, por meio de processo administrativo. }\end{array}$ \\
\hline Plano de carreiras & $\begin{array}{l}\text { - Estender o plano de carreira dos sargentos ao posto de Major, pois vai até } \\
\text { Capitão; } \\
\text { - Aumentar o número de militares promovidos por merecimento, valorizando o } \\
\text { conceito recebido nas avaliações de desempenho; } \\
\text { - Realizar concurso interno aos sargentos que tenham curso superior, } \\
\text { possibilitando-os ingressar no Quadro Complementar de Oficiais (QCO); } \\
\text { - Diminuir o tempo de estabilidade dos sargentos para dois anos, considerando o } \\
\text { tempo de formação como estágio obrigatório. Atualmente, o sargento precisa de } \\
10 \text { anos de efetivo serviço para adquirir estabilidade; } \\
\text { - Promover o sargento reformado a um posto acima. }\end{array}$ \\
\hline $\begin{array}{l}\text { Frustração na carreira } \\
\text { após formação na escola }\end{array}$ & $\begin{array}{l}\text { - Desenvolver nos alunos das escolas de formação um acirrado trabalho } \\
\text { psicológico sobre a carreira militar. }\end{array}$ \\
\hline
\end{tabular}




\section{Conclusões}

O presente estudo teve como finalidade analisar os fatores motivacionais que contribuem para o nível de motivação dos sargentos de carreira do $9^{\circ}$ Grupo de Artilharia de Campanha, bem como buscar possíveis soluções para minimizar aqueles que trazem desmotivação para os mesmos, sem desconsiderar as peculiaridades da organização militar no contexto do serviço público.

No intuito de fornecer embasamento para esta temática, fez-se a necessidade de realizar o estudo específico referente aos conceitos e teorias sobre motivação, visando, assim, adaptá-las com a realidade do problema em questão.

Assim, realizou-se uma pesquisa qualitativa como forma de levantamento de dados, através da técnica de grupo focal, aplicado em alguns sargentos de carreira, no qual foram verificados os fatores que motivam esses profissionais, e os que trazem insatisfação na profissão, levando a uma possível evasão.

Com a realização deste estudo, constatou-se uma série de oportunidades de melhorias, que podem ser implantadas pelo $9^{\circ} \mathrm{GAC}$, no intuito de melhorar o nível de motivação da classe dos sargentos de carreira na unidade e evitar os desejos de evasão por parte destes. $\mathrm{Na}$ análise desses resultados, é de grande relevância a consciência que o escalão superior da instituição e sua gestão deve se preocupar com esses fatores, visando o bem estar dos sargentos, assim como dos outros integrantes da tropa, fazendo com que haja eficiência no desempenho profissional dos militares, e o crescimento institucional.

Manter os sargentos motivados, bem como as outras classes de militares, é de fundamental importância para o cumprimento das missões da organização. Isso valoriza a carreira do militar, tornando-a mais atrativa. Isto é válido para qualquer servidor público, independente do seu campo de atuação. 
Id on Line Revista Multidisciplinar e de Psicoloqia

Id on Line Multidisciplinary and Psycology Journal

\section{Referências}

ALVES, L. C.; SILVA, A. V. L.; E. M. J., OLIVEIRA. Motivação e Recompensas: uma investigação com base nas Teorias da Hierarquia das Necessidades e da Expectativa. Id on Line Revista de Psicologia, v.11, n. 35, maio/2017.

BARDIN, L. Análise de Conteúdo. Lisboa: Edições 70, 1979.

BERGAMINI, C. W. Psicologia aplicada à Administração. São Paulo: Atlas, 1982.

BERGAMINI, C. W. Motivação nas organizações. 4. ed. São Paulo: Atlas, 1997.

BRASIL (a). Constituição. Constituição da República Federativa do Brasil. Brasília, DF, 1998.

BRASIL (b). Estado Maior do Exército. R-3: Regulamento de Administração do Exército. Brasília, 1990.

BRASIL (c). Estado Maior do Exército. R-4: Regulamento Disciplinar do Exército. Brasília, 2004.

BRASIL (d). Exército Brasileiro. Estado Maior. IP 20-10: Instruções Provisórias IP 20-10 LIDERANÇA MILITAR - Brasília, DF, 1991.

BRASIL (e). Lei Complementar $\mathbf{n}^{\mathbf{0}}$ 97/1999. Dispõe sobre as normas gerais para a organização, o preparo e o emprego das Forças Armadas. Diário Oficial da União. Brasília, 10 jun. 1999. Acesso em: 30 jul. 2016. Disponível em: <http://www2.camara.leg.br/legin/fed/leicom/1999/leicomplementar-97-9-junho-1999377583-publicacaooriginal-1-pl.html>

CAFFÉ FILHO, H. P.; GONÇALVES, M. C. A.; SANTOS, N. L. Motivação no serviço público: a relação entre a motivação e a qualidade do serviço público sob uma perspectiva geral. Id on Line Revista de Psicologia, v.11, n. 36, julho/2017.

CARVALHO, J. M. Forças Armadas e política no Brasil. Rio de Janeiro: Editora Jorge Zahar, 2005. 1939-C324f.

CORADI, C. D. O comportamento humano em administração de empresas. São Paulo: Pioneira, 1985.

EUGÊNIO, M. Pirâmide de Maslow: A importância da teoria para o seu negócio. Disponível em: <https://mktderelacionamento.com.br/author/omktderelacionamento/page/2/> Acesso em: 09 jul. 2017. 2016. 
EXÉRCITO BRASILEIRO. 9 GRUPO DE ARTILHARIA DE CAMPANHA - GRUPO MAJOR CANTUÁRIA. Histórico. Disponível em: <www.9gac.eb.mil.br/historico-da-om> Acesso em: 09 jul. 2016. 2015.

FERREIRA, A. A.; REIS, A. C. F.; PEREIRA, M. I. Gestão Empresarial: de Taylor aos nossos dias - Evolução e Tendências da Moderna Administração de Empresas. São Paulo: Thomson Learning, 2002.

GIL, A. C. Gestão de pessoas: enfoque nos papéis profissionais. São Paulo: Atlas, 2001.

HERZBERG, F. I. One more time: how do you motivate employees? Harvard Business Rewiew, Boston, v. 46, 1968.

HERZBERG, Frederick. Novamente: como se faz para motivar funcionários? Biblioteca Harvard de Administração de Empresas, São Paulo: v.1, n. 13, 1975.

JONES, Gareth R.; GEORGE, Jennifer M. Fundamentos da Administração Contemporânea. 4. ed. Porto Alegre: AMGH Editora, 2012.

LACOMBE, Francisco José M. Recursos humanos: princípios e tendências. São Paulo: Saraiva, 2005.

LEWIN, K. Principles of Topological Psychology. New York: McGraw-Hill Book Company, 1936.

MAGILL, R. A. Aprendizagem motora: conceito e aplicações. São Paulo: Edgard Blücher. 1984.

MASLOW, A. H. A theory of human motivation. Psychological Review, v. 50, p. 390-6, 1943.

MAXIMIAnO, A. C. A. Teoria Geral da Administração. 6. ed. São Paulo: Atlas, 2007.

McGREGOR, D. O lado humano da empresa. São Paulo: Martins Fontes, 1992.

MINAYO, M. C. S.; SANCHES, O. Quantitativo-Qualitativo: Oposição ou Complementaridade? Caderno de Saúde Pública, Rio de Janeiro, v. 9, n. 3, p. 239-262, jul/set 1993.

MORGAN, D. L. Focus group as qualitative reseach. London: Sage, 1997.

PORDANOV, C. C.; FREITAS, E. C. Metodologia do Trabalho Científico: Métodos e Técnicas de Pesquisa e do Trabalho Acadêmico. Novo Hamburgo, 2. ed. 2013. Disponível em: $\quad$ www.faatensino.com.br/wp-content/2014/11/2.1-E-book-Metodologia-do-TrabalhoCientifico-2.pdf. Acesso em: 09 jul. 2016. 
REGO, Gen Ex Luiz Edmundo Montedônio. Valores Observados no Exército Brasileiro. Revista da Cultura - Edição 19. Janeiro, 2012. Acesso em: 09 jul. 2016. Disponível em: www.defesanet.com.br/doutrina/noticia/19229/Valores-Observados-no-Exército-Brasileiro.

RESERVAER. Clube Virtual dos Militares da Reserva e Reformados da Aeronáutica. Disponível em: <http://www.reservaer.com.br/est-militares/desmotivacao.html> Acesso em: 29 jul. 2017. 2017.

ROBBINS, S. P. Comportamento organizacional. 9. Ed. São Paulo: Prentice Hall, 2004. SM. Sociedade Militar. Acesso em: 29 jul. 2016. Disponível em: $<$ http://www.sociedademilitar.com.br/wp/2016/01/militares-insatisfeitos-com-oscomandantes-abrem-a-boca-novos-tempos.html>

VERGARA, Sylvia Constant. Projetos e relatórios de pesquisa em administração. 5. ed. São Paulo: Atlas, 2004.

Como citar este artigo (Formato ABNT):

RAIMUNDO, João N.; CORREIA-NETO, Jorge da S. Motivação e Evasão na Carreira Militar: um estudo de caso no Exército Brasileiro. Id on Line Revista Multidisciplinar e de Psicologia, 2017, vol.11, n.37, p. 699717. ISSN: $1981-1179$

Recebido: $28 / 09 / 2017$

Aceito: 29/09/2017 